\title{
PHARMACEUTICAL MARKETING IN INDIA: NEED TO REPLANISH
}

\author{
Prajjwal Thakur \\ School of Pharmaceutical sciences. \\ CT University, Ludhiana, Punjab, India \\ Dr. Harpreet Kaur Boparai \\ School of Pharmaceutical sciences. \\ CT University, Ludhiana, Punjab, India
}

\begin{abstract}
This paper audits current showcasing rehearses in the drug area, and their effect on customer what's more, specialist conduct. It recognizes negative effects which incorporate deceiving promoting, sickness mongering and raising expenses. It contends the need to move from industry self-guideline to an autonomously observed code of training for drug showcasing.
\end{abstract}

Keywords - Pharmaceutical marketing, Marketing strategy, Healthcare sectors, Direct to Consumer Advertising.

\section{INTRODCUTION}

Drug industry throughout the years has come about to quite possibly the most interesting industry as it serves the general public deeply, it gives work as well as saves a great many lives with its medications and inoculations. Pharm. Industry has been set apart as most inventive industry in the over a significant time span for the world turn of events. India is the world's quickest developing economy with its second biggest populace on the planet makes India a push for the improvement of the Indian Pharmaceutical sector. India today has an exceptional segment favorable position and disservice simultaneously, attributable to its enormously huge populace. India is home to around 1.3 billion individuals or around $1 /$ seventh of the world's populace. The bit of leeway remains that a particularly gigantic populace makes us an exceptionally enormous and alluring business sector, also that populace is youthful, or we may not be right in expressing it as the most youthful on the planet. The burden surely is that the per capita essential drug is likewise high inferable from the difficult financial conditions that exist.

\section{SCOPE OF THE STUDY}

Publicizing being a bit of human science is significantly amazing and complex in nature. The fast changes in various territories have gotten uncommon changes publicizing. By and large, promoting was stressed over buying and selling of product and ser-vices just but at this point its augmentation has extended and it incorporates an extent of activities from purchaser satisfaction to customer euphoria and the heads of customer relationship.

\section{GOAL OF STUDY}

- To examine the current standard working techniques.

- To consider Different sorts of business sectors accessible to sell the items.

- To read technique for trading and the advantages of pharmaceutical marketing.

\section{RESEARCH OF THE MARKET OF} MEDICAL PRODUCTS

Statistical surveying is data premise of accomplishment of such purposes, as specific deals volume, creation and a dispatch available of new merchandise, increment in piece of the overall industry. Prime an incentive in statistical surveying gets concentrating of ware structure. For this situation the idea «market» is related to idea. As ware market comprehend circle of item deals (or gatherings of merchandise) which interconnected by specific properties. Object of items' statistical surveying is an equality of market interest in certain financial and social conditions.

Direction of complex examination of the market: 
- concentrating of market prerequisites to item, for example of purchasers' necessities and, that is particularly significant, end clients to shopper estimation of item.

- complex exploration of the market foreordaining cautious concentrating of a monetary conjuncture.

- examination of market division and exploration of isolated market fragments with the end goal of the further noteworthy of the objective business sectors.

- concentrating of firm structure available, for example characterizing of fundamental gatherings

of firms working in the given market: firmsaccomplices (purchasers), firms competitors, which yet have not demonstrated revenue corresponding to the given products, however can be considered as likely purchasers or dynamic accomplices.

\section{PROCESS OF MARKETING MANAGEMENT}

Advertising the executives is the examination, arranging, a usage the authority over activities, pointed on a foundation, securing and backing of ideal trades with target purchasers for the accomplishment of certain issues of the association, such, as benefit gathering, deals volume development, increment piece of the overall industry, and so forth The issue of promoting the board comprises in impact on level, time and character of interest that it assisted the association with accomplishing purposes.

For the board of advertising action of the endeavor four gatherings of inquiries have the best worth:

1. Data

2. Utilization of components (complex) of promoting

3. Association of promoting movement

4. Control in showcasing circle.

\section{STAGES OF MARKETING RESEARCH}

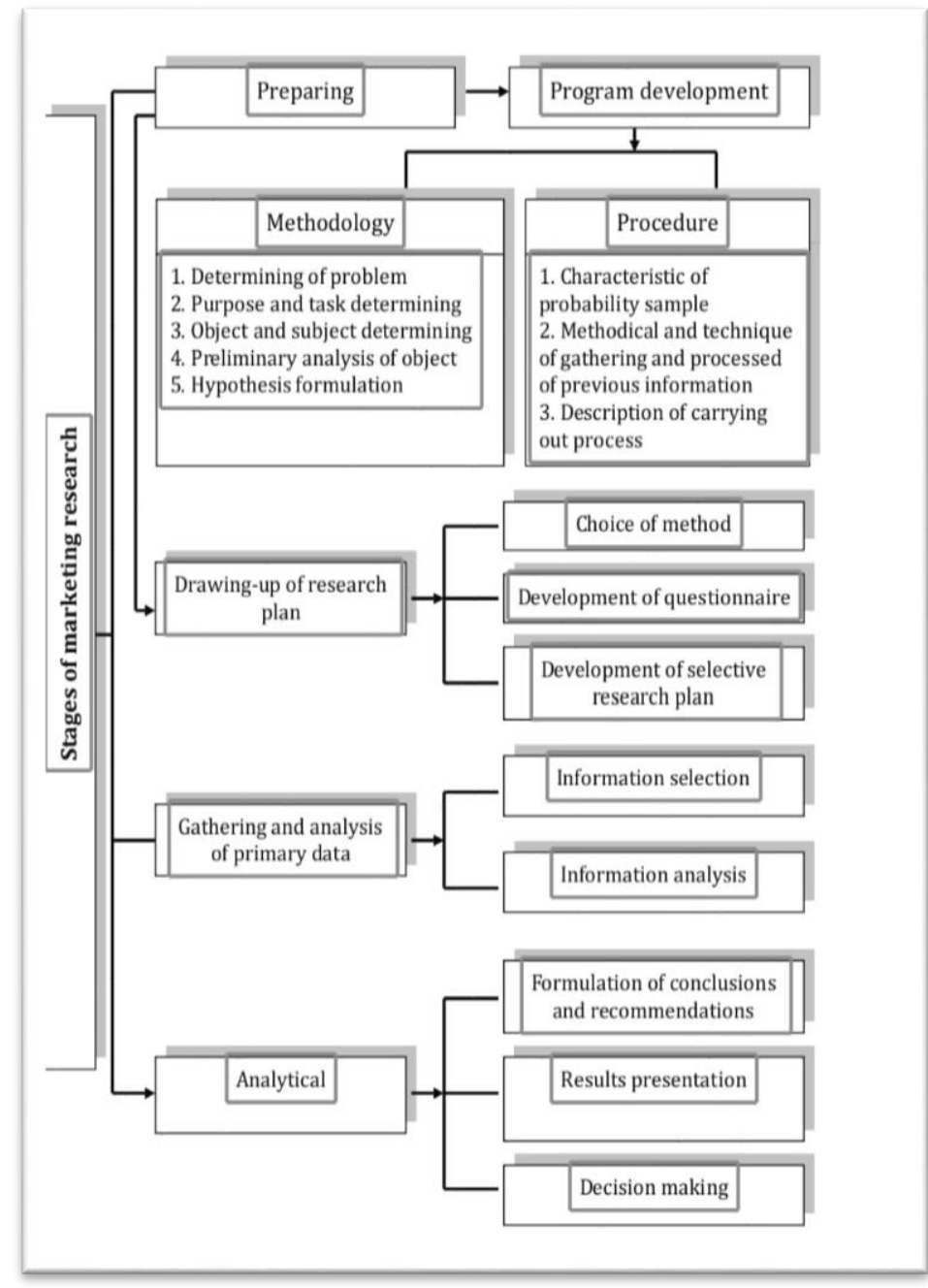

\section{THE VALUE OF THE PHARMACEUTICAL INFORMATION}

The data speaks to a bunch of the arranged archive documents and data innovations which give data measures based on normalized types of accommodation and information transmission, structures and strategies for delivering of data administrations of various kind. Data is critical in states of the market - for the producer, discount, retail exchange. The data available, variety of merchandise, request, a market limit, a portion of the different associations, conveyance channels, publicizing utilizes the best interest. Wellsprings of this data are addressing, shows, classes, reasonable handouts, value records, occasional or uncommon versions, measurable assortments, the topical indexes, the specific information bases. Aside from the data available the data on the inner climate (deductively specialized potential, the staff, mechanical saves and 


\section{International Journal of Engineering Applied Sciences and Technology, 2020 \\ Vol. 5, Issue 8, ISSN No. 2455-2143, Pages 174-179 \\ Published Online December 2020 in IJEAST (http://www.ijeast.com)}

stocks, creation costs, benefit productivity of arrival of merchandise, evaluating), just as the data on the climate (segment, monetary, climatic, logical specialized, political, social) is utilized.

Ownership of different data and its utilization in interests of the venture is the primary vital state of advertising. Incentive in showcasing the executives causes significant standards of data development: Desperation, that is genuine ideal presentation of the advertising climate condition (in the best business data sets the data is refreshed day by day);

Unwavering quality - gives a precise recreation of a condition and improvement of production, the market, a climate. Regarding need of safeguarding by the undertaking of serious positions different wellsprings of the data ought to be utilized, and the got information ought to be dissected on nonappearance of inconsistencies.

Pertinence of information - data development as indicated by specific prerequisites. Fulfillment of show - is important for the target record of all factors framing or impacting of condition and improvement of the showcasing climate.

Deliberateness of information - centers around explicit objectives and assignments The coordination and data solidarity - require such arrangement of markers' working out which logical inconsistencies in ends would not be assumed, irregularity of the essential and got information. In the states of the market economy such sorts of the data are utilized: strategic; business (about a market interest) outside.

\section{MARKETING INFORMATION SYSTEMS}

A showcasing data framework (MIS) is a bunch of strategies and techniques intended to produce, investigate, spread, and store foreseen showcasing choice data on a customary, consistent premise. A data framework can be utilized operationally, authoritatively, and deliberately for a few parts of advertising. A promoting data framework can be utilized operationally, authoritatively, and deliberately for a few parts of advertising.

No advertising movement can be completed in disconnection, it doesn't work in seclusion that implies there are different powers could be outside or inner, controllable or wild which are chipping away at it. Along these lines to know which powers are following up on it and its effect the advertiser needs to gettogether the information through its own assets which regarding showcasing he is attempting to assemble the market data or structure a showcasing data framework. This assortment of data is a nonstop cycle that accumulates information from an assortment of sources combines it and sends it to those answerable for meeting the commercial centers needs.

The viability of advertising choice is demonstrated on the off chance that it has a solid data framework offering the firm a Competitive favorable position. Promoting Information ought not be drawn closer in an inconsistent way. On the off chance that exploration is done thusly, a firm could confront these dangers:

1. Openings might be missed.

2. There might be an absence of consciousness of ecological changes and contenders' activities.

3. Information assortment might be hard to dissect throughout a few time spans.

4. Showcasing plans and choices may not be appropriately looked into.

5. Information assortment might be disconnected.

6. Past investigations may not be put away in a simple to utilize design.

7. Delays may result if another investigation is required.

8. Activities might be traditionalist instead of expectant. The absolute data needs of the advertising office can be determined and fulfilled through a promoting insight organization, which contains three parts.

\section{RESEARCH OF CONSUMERS AND A TYPOLOGY OF MEDICINES' CONSUMPTION}

Autonomous gathering of exploration is the investigation of utilization, the customer needs and the thought processes of conduct available. Investigation of inspiration and buyers' conduct use in the following displaying of these cycles. By and large, the conduct of buyers in the market contrasts as per needs and targets of market exercises, inspiration, and so on In any case, buyer conduct has some shared characteristic. In the market of their conduct can be communicated by monetary, social and mental variables that portray explicit requirements. Assortment factors affecting shopper conduct and, principally outer climate factors. Becomes significant elements of individual contrasts of buyers: pay, 


\section{International Journal of Engineering Applied Sciences and Technology, 2020 \\ Vol. 5, Issue 8, ISSN No. 2455-2143, Pages 174-179 \\ Published Online December 2020 in IJEAST (http://www.ijeast.com)}

inspiration, information, devotion and excitement, individual way of life, socioeconomics, and so forth Normally designate association customers and end clients. They vary in method of utilization products and ventures and what to purchase. The associations (undertakings) - clients incorporate assembling organizations, wholesalers and retailers, government offices and different charities associations. In the field of drugs these are drug makers, wholesalers, affiliates, drug stores, clinics, and so on End-clients are the people (singular buyers), family families (one or a few families joined by a typical family). Highlight of purchasers of medications is that their conduct is to a great extent subject to the arrangement of specialists related with the infection or its avoidance. The primary goal of showcasing expert is to recognize the items who settle on choices about buying products.

"Purchaser" and "client" in advertising are unmistakably content. Clients - are the individuals who are straightforwardly engaged with the buy.

Shoppers - a more extensive idea they are subjects who fulfill their requirements. The issue of big business is uncover, study and gauge precisely solid need, for which fulfillment movement is coordinated.

Ideas "need", "request" and "utilization" are interconnected also, before to portray orderly ways to deal with their exploration, will result meaning of these ideas. Need in something, dispassionately essential for capacity to live and advancement of the individual, social gathering, a general public all in all.

Request - public or an individual need in material advantages and administrations, in methods for creation and the purchaser products, given cash assets.

Utilization - utilization of an item over the span of fulfillment of needs, a last period of cycle of propagation. For anticipating of need pointers, request and utilization at the first examination stage and the investigation is utilized of the most target rule utilization.

In that examination assign such angles: changes in utilization (elements), the sizes and structure of utilization concerning diverse spending units (for instance, on 1 occupant, on 1 or 1000 patients, and so forth); reasons of separation of utilization; meaning of a least of utilization (or ideal sizes). Highlight of meds as utilization items is that they can't be chosen by the patient (aside from the non-recommend drugs), arrangement by specialist is fundamental. Utilization of clinical items is impacted by presentation of new strategies for treatment, level of security meds of a drug stores chain, an individual decision by specialists of isolated clinical items or their gatherings, decrease or the full end of interest for certain arrangements inferable from their supplanting with more successful, and so forth. For a foundation of laws of isolated clinical items gatherings utilization and working out of strategies for needs definition for them concentrating of highlights of their application is vital. Generally speaking, the plans which have been worked out by specialists, narratives of ailments and sheets of the arrangements, commonplace plans of treatment separate nomological structures of illnesses are with that end in view broke down.

\section{STUDYING OF THE NEED FOR MEDICAL PRODUCTS:}

Strategies for meaning of the requirement for clinical items are different contingent upon gathering of a clinical item:

1. Meds of explicit activity.

2. Prescriptions, which utilization is carefully standardized.

3. Clinical results of a wide range of activity.

Tackling of the requirement for explicit activity clinical items (powerful concerning activators of discrete infections: for treating diabetes, impacting on the stomach related framework, and so forth) and specifically chipping away at isolated utilitarian frameworks of a living being (antituberculosis, and so on).

\section{MARKETING STRATEGIES OF PHARMACEUTICAL ENTERPRISES:}

Dynamic on production of merchandise ought to be founded on the vital methodology. That is to say, that any choice in the given region ought to be acknowledged, thinking about an association extreme objective. The broad word reference of money manager makes such meaning of idea «marketing strategy» (methodology of inclusion of the market): this is arrangement and acknowledgment of purposes and issues of the venture maker and the exporter on each different market (a market portion) and every merchandise for the specific timeframe (long haul, middle of the road term) for acknowledgment of modern and business movement in full similarity of a market circumstance what's more, chances of the endeavor (firm). Promoting system speaks to the program of showcasing action of firm at the objective business sectors, characterizing essential choices on accomplishment of promoting purposes. 


\section{International Journal of Engineering Applied Sciences and Technology, 2020 \\ Vol. 5, Issue 8, ISSN No. 2455-2143, Pages 174-179 \\ Published Online December 2020 in IJEAST (http://www.ijeast.com)}

Acknowledgment of advertising methodology is done in the states of rapidly changing climate of the firm which record is conceivable just in transient plans, for example in systems of «marketing tactics». It likewise arrangement and acknowledgment of organization's issues at the different business sectors (portions) and on every products, except just during the solid timeframe (present moment) based on a promoting system and an assessment of a current market circumstance with a steady adjusting of issues taking into account changes of strategic and different variables.

A system of the single-fragment focus includes choosing as the objective market one homogeneous portion from inside the all-out market. One promoting blend is then evolved to arrive at this single portion. A little organization might need to focus on a solitary market portion, as opposed to take on numerous rivals in an expansive market. This system empowers an organization to enter one little market secure a standing as a trained professional or then again, a specialist in this restricted market. They can enter such a market with restricted assets. Also, as long as the single section remains a little market, huge rivalries are probably going to disregard the single-section trained professional.

\section{COMMODITY POLICY OF THE PHARMACEUTICAL ENTERPRISES:}

After a decision of advertising technique the venture (firm) characterizes advertising instruments of effect on shoppers by products, for example the product strategy. The item strategy is a precise company's movement which compares to showcasing procedure; it is coordinated on examining methods of the intensity increment of let out creation, above all else, its subjective qualities, formation of new merchandise, making up the variety and the executives, the inquiry of market portions, improvement and acknowledgment of the pressing methodology, brand names, administration of the products.

\section{ADVERTISING AND ITS ROLE IN THE COMMUNICATION POLICY OF THE ENTERPRISES:}

Data about promoting practice, there are even records in the main composed stories. The heralds of presentday publicizing were painting the dividers, rocks, road telecasters, marked items to the craftsman.

Advertising appears in four roles: marketing, communication, economic and social.
The showcasing job comprises in effect on an objective market through every one of the components of promoting, in light of the fact that it incorporates an instrument for the move of client data, thus, promoting is a segment of promoting interchanges.

The open job is that publicizing is a type of mass correspondence. It communicates different sorts of promoting data to accomplish understanding among purchasers and venders on the lookout.

On monetary job of the framework, there are two perspectives concerning the effect of promoting on the economy. From the situation of the main (school market power) promoting it is the open instruments of influence utilized by market experts to occupy purchasers from the cost, in terms of the second (school market rivalry) publicizing is viewed as a wellspring of data, which expands the affectability of buyers to cost and animate rivalry. At the undertaking level monetary or business part of promoting seems to expand the deals of products or benefit.

The social job of publicizing:

1. Publicizing educates about the better than ever items.

2. Encourages correlation of items, empowering the purchaser to make a choice on the buy.

3. Publicizing affects individuals.

4. Advancement of publicizing is somewhat a marker of social advancement. Publicizing can be seen as a type of correspondence that endeavors to decipher the nature of merchandise and ventures on the language of buyers.

\section{MARKETING CONTROL}

Control as one of the elements of the executives, finishing the way toward showcasing exercises and decide how viable work the firm. First of this is a structure deliberate activity on staff of the organization, orderly observing of his exercises, a correlation of the genuine condition of the set up standards. Control (review) advertising is a profound the logical work as the outcome of which the administration of organization fined new strategies for showcasing the executives, devices, and instruments of activity or variation to the variables of inside and outside climate.

Control of showcasing incorporates assessment of the usage of advertising procedures and executing remedial activities to accomplish their objectives. The fundamental boundaries of control are volume deals, 
overall revenues and costs, shopper reaction on new items and administrations, consistence with the arranged and real aftereffects of modern and business exercises. Promoting control permits the organization to decide the adequacy of advertising openings.

As a component of the endeavor promoting the board controls ought to be completed in such ways:

1. Consistence with the arranged pointers of real outcomes.

2. Control of benefit creation and business endeavors exercises.

3. Vital control and inspecting of promoting.

Investigation of deals dependent on quantitative pointers will evaluate the attainability of utilizing an advertising technique. Primary information sources are accounts that contain data about the buyer, the quantity of requested products, addressed the cost, terms of procurement, district, date of procurement, states of transportation.

\section{ADVANTAGES}

- Long haul and stable business.

- Highly paid business sectors: Price acknowledgment is more in these business sectors.

- Even client likewise can't change the source because of administrative methodology engaged with the equivalent.

- Even client likewise can't change the source because of administrative methodology engaged with the equivalent.

- Even client likewise can't change the source because of administrative methodology engaged with the equivalent.

Customers can not change the source effectively in light of the fact that it is quite costly cycle and time taking cycle.

\section{KEY STRENGTHS OF PHARMA SECTOR}

- Ease of development/Manufacturing/Capex costs/use to run a CGMP consistence office.

- Ease logical pool on shop floor prompting great documentation.

- Demonstrated history in plan of innovative assembling offices.

- Great administrative consistence capacities for working these resources.
- Ongoing achievement history in going around API/definition licenses.

- About $95 \%$ of the homegrown necessity being met through homegrown creation.

\section{REFERENCES}

1. (2019) sept; International Bulletin of Management and Economics, vol-XI.

2. Professor Mnushko Z. (2016); Management and marketing in Textbook-II, Chapter-2 (page no. 26-31).

3. Professor Mnushko Z. (2016); Management and marketing in Textbook-II, Chapter-4 (page no. 55-64).

4. Professor Munshko Z. (2016); Management and marketing in Textbook-II, Cha 